\title{
Analisis Intensitas Cahaya pada Gedung Central Medical Unit di Rumah Sakit Umum Daerah Prof.DR. H. Aloei Saboe Kota Gorontalo
}

\author{
Yunan Daud \\ IPS Rumah Sakit \\ RSUD Prof. DR. H. Aloe Saboe \\ Gorontalo, Indonesia \\ yunandaud123@gmail.com
}

\author{
Frengki Eka Putra Surusa \\ Program Studi Teknik Elektro \\ Universitas Ichsan Gorontalo \\ Gorontalo, Indonesia \\ kiki.alaska@gmail.com
}

\author{
Steven Humena \\ Program Studi Teknik Elektro \\ Universitas Ichsan Gorontalo \\ Gorontalo, Indonesia \\ steven.humena@unisan.ac.id
}

\begin{abstract}
Abstrak-Peraturan Menteri Kesehatan Republik Indonesia (PERMENKES RI) No. 24 Tahun 2016 Tentang Persyaratan Teknis Bangunan dan Prasarana Rumah Sakit pada pasal 22 ayat 4 menjelaskan bahwa sistem pencahayaan harus direncanakan berdasarkan tingkat iluminasi yang dipersyaratkan sesuai fungsi Ruang Bangunan Rumah Sakit. Gedung Central Medical Unit (CMU) pada Rumah Sakit Umum Daerah (RSUD) Prof. Dr. H. Aloei Saboe Kota Gorontalo adalah sebagai objek penelitian, yang bertujuan untuk mengetahui intensitas pencahayaan apakah memenuhi standar. Metode yang digunakan untuk penelitian ini adalah dengan cara observasi, wawancara, dan pengukuran, kemudian diolah menggunakan metode deskriptif sehingga data yang valid dari hasil pengukuran dan melakukan perhitungan mengacu pada standarisasi, kemudian membandingkan hasil pengukuran. Hasil penelitian menunjukan bahwa tingkat pencahaayaan atau lux rata-rata untuk semua ruangan masih dibawah standardisasi yaitu $80 \%$ dari standar yang telah ditentukan, iluminasi yang terendah pada ruangan CSSD (Ruang Steril) sebesar 20 lux dan seharusnya 200 lux, sedangkan yang tertinggi terdapat diruangan IGD (Ruang Tindakan) sebesar 95 lux dan seharusnya 300 lux, sehingga dapat dikategorikan dibawah standar. Hal ini dikarenakan pengaruh luas ruangan yang tidak sesuai dengan jumlah lampu yang terpasang, kondisi lampu yang sudah kusam/kotor sehingga cahaya yang keluar dari lampu tidak dapat keluar secara maksimal, armatur pada titik lampu kurang bersih sehingga cahaya yang keluar terhalang oleh debu, dan warna dinding sudah mulai pudar sehingga visualisasi cahaya tidak keluar secara maksimal.
\end{abstract}

Kata Kunci-Intensitas Cahaya, RSUD Aloei Saboe, PERMENKES RI.

\section{PENDAHULUAN}

Rumah Sakit Umum Daerah (RSUD) Prof. Dr. H. Aloei Saboe Kota Gorontalo yang berada di Ibu kota Provinsi Gorontalo dan terletak dipusat wilayah Teluk Tomini, yang dapat memudahkan masyarakat untuk mengakses pelayanan rujukan, dengan kata lain sebagai pusat rujukan. Untuk itu dilakukan pembenahan baik dari segi sarana/prasarana, sumber daya manusia, serta jenis pelayanan yang diberikan [1].

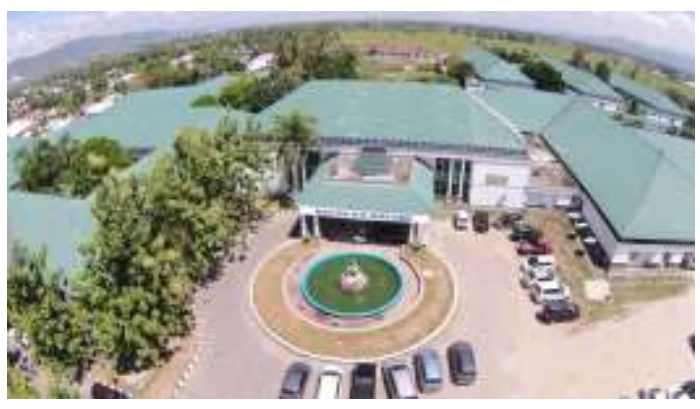

Gambar 1. RSUD Prof. Dr. H. Aloei Saboe

Program kesehatan merupakan salah satu hal yang di prioritaskan oleh pemerintah nasional dalam mewujudkan Indonesia sehat dan mandiri. Kesehatan adalah tanggung jawab bersama dari setiap individu, masyarakat, pemerintah ataupun swasta [2]

Pemerintah telah mengeluarkan kebijakan tentang pentingnya penghematan energi. Hal ini tertuang dalam Instruksi Presiden (INPRES) No. 13 Tahun 2011 Tentang Penghematan Energi dan Air, yang terutama ditunjukan terhadap pencahayaan gedung [3].

Pencahayaan merupakan salah satu faktor penting untuk menciptakan lingkungan kerja yang baik dan akan memberikan kenyamanan pada pekerja [4]. cahaya yang terlalu terang dapat mengganggu penglihatan begitu juga sebaliknya.

RSUD Prof. Dr. H. Aloei Saboe memiliki beberapa bangunan atau gedung yang diantaranya adalah Central Medical Unit (CMU) yang terdiri dari 8 ruangan yaitu:

- Instalasi Gawat Darurat (IGD)

- Instalasi Bedah Sentral (IBS)

- Instalasi Rawat Darurat Anak (IRDA)

- Paediatric Intensive Care Unit (PICU)

- Intensive Care Unit (ICU)

- Neonatel Intensive Care Unit (NICU)

- $\operatorname{Verlos}$ Kamer (VK)

- $\quad$ Central Sterile Supply Department (CSSD)

Penelitian ini membahas sistem pencahayaan pada gedung CMU di RSUD Prof.DR.H Aloei Saboe, yang 
bertujuan untuk mengetahui intensitas pencahayaan setiap ruangan perawatan pada gedung CMU, apakah sesuai standar PERMENKESRI No.24 Tahun 2016 [5].

\section{TINJAUAN PUSTAKA}

Audit energi adalah suatu analisis terhadap konsumsi energi dalam sebuah sistem yang menggunakan energi., seperti gedung pabrik dan sebagainya, hasil dari audit energi laporan tentang bagian yang mengalami pemborosan energy [6].

Tingkat pencahayaan pada suatu ruangan didefinisikan sebagai tingkat pencahayaan rata rata pada bidang kerja dalam satuan lux. Yang dimaksud dengan bidang kerja bidang horizontal imajiner yang terletak 0,75 meter diatas lantai pada seluruh ruangan [7].

Jenis kegiatan yang dilakukan di dalam ruangan akan menentukan tingkat iluminasi yang dibutuhkan, karena jenis kegiatan yang berbeda akan memerlukan tingkat iluminasi yang berbeda sesuai dangan luas ruangan dan tingkat iluminasi yang dipersyaratkan.

Berikut ini di jelaskan pengertian dari setiap ukuran ukuran dasar teknik pencahayaan:

1. Arus Cahaya $(\Phi)$ adalah jumlah cahaya total yang dipancarkan oleh sebuah...sumber... (ahæaya dalam satu detik, satuannya Lumen (lm).

$$
\begin{aligned}
& \Phi=E \times A \quad \text { atau } \\
& \Phi=W \times \frac{L}{w}
\end{aligned}
$$

dimana :

$\mathrm{W}=$ daya Lampu.

L/W = Luminous efficacy Lamp / Lumen per Watt.

Untuk Menentukan nilai Luminous Efficacy/Lumen Per Watt dapat dilihat pada Box/kotak lampu yang di beli secara umum.

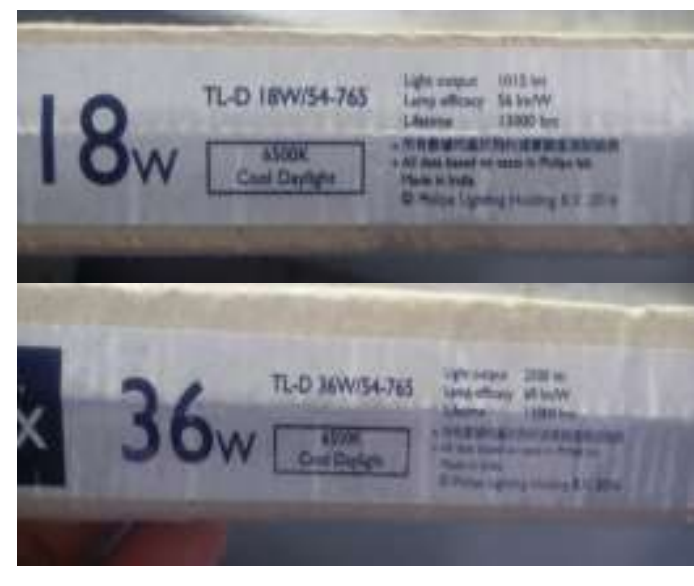

Gambar 2. Luminous efficacy Lamp

2. Kepadatan cahaya adalah arus cahaya yang dipancarkan ke satu arah tertentu per satyan sudut ruangnya, satuannya Candela (cd). Dengan persamaan (2).

$$
I=\frac{\Phi}{\omega}
$$

dimana;

$\omega \quad=$ sudut ruang satuan steradian

3. Intensitas Cahaya/ Iluminasi (E) adalah Arus cahaya yang jatuh pada permukaan sebuah bidang per meterpersegi, satuannya Lux atau Lumen/m². Dengan persamaan (3).

$$
E=\frac{\Phi}{A}
$$

dimaan;

$\mathrm{A}=$ luas permukaan yang di terangi satuan $\mathrm{m}^{2}$ atau $\mathrm{cm}$

Kuat pencahayaan pada suatu ruangan pada umumnya didefinisikan sebagai tingkat pencahayaan pada bidang kerja. Yang dimaksud dengan bidang kerja ialah bidang horizontal imajiner yang terletak 0,75 meter di atas lantai pada seluruh ruangan. Merujuk rumus yang dikemukakan Schiler (1992), kuat pencahayaan dapat dihitung dengan persamaan (4).

$$
E=(I \times C U \times L L F \times) / A
$$

dimana:

$$
\begin{array}{ll}
\mathrm{E} & =\text { Kuat pencahayaan (lux). Atau } \\
\mathrm{I} & =\text { Intensitas sumber cahaya (lm). } \\
\mathrm{CU} & =\text { Faktor Utilisasi. } \\
\mathrm{LLF} & =\text { Faktor rugi cahaya. } \\
\mathrm{A} & =\text { Luas ruangan (Guntur et al., 2017). }
\end{array}
$$

Perhitungan kuat pencahayaan rata-rata diperoleh dari hasil pengukuran kuat pencahayaan yang diambil dari beberapa tempat di dalam ruangan dengan menggunakan luxmeter, menggunakan persamaan (5).

$$
\text { Erata }- \text { rata }=\left(E_{-} 1+E_{-} 2+E_{-} 3 \ldots+E_{-} n\right) / n
$$

dimana :

E1...n = Hasil pengukuran kuat pencahayaan dibeberapa tempat.

Erata-rata $=$ Kuat pencahayaan rata-rata satuan Lux.

Sedangkan untuk menghitung intensitas sumber cahaya, menggunakan persamaan (6).

$$
I=i \times n
$$

dimana :

I = Intensitas sumber cahaya ( $\mathrm{lm})$.

$\mathrm{i} \quad=$ Tingkat pencahayaan pada lampu yang dipakai (lm).

$\mathrm{n} \quad=$ Jumlah sumber cahaya.

4. Luminasi (L) adalah Kepadatan cahaya per meter persegidari satu bidang permukaan yang dapat terlihat oleh mata, satuannya $\mathrm{cd} / \mathrm{m}^{2}$. Dengan persamaan (7).

$$
L=\frac{I}{A}
$$

Penerangan merupakan bagian yang terpenting di dalam suatu instalasi listrik, namun didalam instalasi penerangan 
tersebut tidak terlepas dari aturan yang di standarisasi pada PUIL 2011 sehingga untuk menentukan jumlah titik lampu serta lumen lampu pada suatu ruang memiliki standarisasi yaitu $80 \%$ dari standar yang telah ditentukan. Sehingga dapat dikategorikan dibawah standar berdasarkan PUIL 2011 [8].

Jumlah lampu pada suatu ruang ditentukan atau dapat dihitung dengan menggunakan persamaan (8) sebagai berikut [9]. :

$$
N=\frac{E \times L \times W}{\Phi \times L L F \times C U \times n}
$$

Keterangan:

$\mathrm{N}$ = Jumlah lampu

$\mathrm{E}=$ Kuat Penerangan/iluminasi (Lux)

$\mathrm{L} \quad=$ Panjang Ruangan (meter)

$\mathrm{W}=$ Lebar Ruangan (meter)

$\Phi=$ Flux cahaya (Lumen)

LLF = Light Loss factor /Faktor Cahaya Rugi $(0,7-0,8)$

$\mathrm{CU}=$ Coefisien of Utilization/Faktor Pemanfaatan $(50 \%$ $65 \%$ )

$\mathrm{n}=$ Jumlah lampu dalam 1 titik lampu.

\section{METODE}

Metode yang digunakan untuk penelitian ini adalah dengan cara observasi, wawancara, dan pengukuran. Cara pengumpulan data yaitu observasi ruang (tempat). Alasan penelitian melakukan observasi adalah menyajikan gambaran realitik, untuk menjawab pertanyaan, serta membantu mengerti perilaku manusia, dan untuk evaluasi yaitu melakukan pengukuran terhadap aspek tertentu. Hasil pengumpulan data diolah dengan metode deskriptif. Data di olah secara analisis univariat dengan cara menganalisis data dalam tabel.

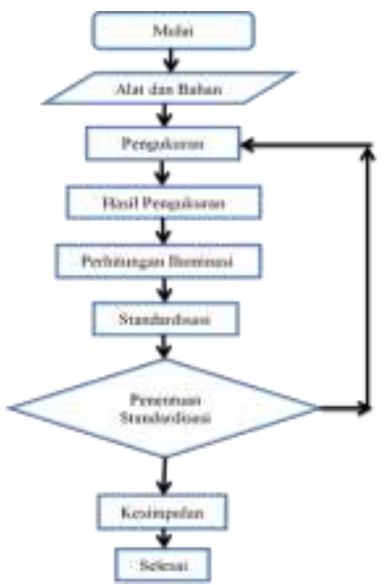

Gambar 3. Alur Penelitian

\section{HASIL DAN PEMBAHASAN}

\section{A. Pengukuran Iluminasi Ruangan IGD}

Ruangan IGD didalamnya ada beberapa ruang, yaitu IRD Triage, Resusitasi, Tindakan, Observasi dan Trauma bedah. Pelayanan di ruang gawat darurat termaksud daerah pelayanan kritis oleh karena itu harus di perhatikan faktor keselamatan salah satunya yaitu sistem penerangannya. Dari hasil pengukuran lampu yang terpasang dapat dilihat pada Tabel I.

TABEL I. HASIl PENGUKURAN ILUMinASI RUANGAN IGD

\begin{tabular}{|c|c|c|c|c|}
\hline \multirow{2}{*}{$\begin{array}{l}\text { Nama } \\
\text { ruang/sub } \\
\text { ruangan }\end{array}$} & \multirow{2}{*}{$\begin{array}{l}\text { Luas } \\
\text { Ruangan } \\
(\mathrm{m} 2) \mathrm{A}\end{array}$} & \multicolumn{2}{|c|}{ Hasil Pengukuran } & \multirow{2}{*}{$\begin{array}{c}\text { Standar Iluminasi } \\
\text { PERMENKES RI } \\
\text { (Lux) }\end{array}$} \\
\hline & & $\begin{array}{l}\text { Siang } \\
\text { (Lux) }\end{array}$ & $\begin{array}{c}\text { Malam } \\
(\text { Lux })\end{array}$ & \\
\hline IRD Triage & 71.25 & 35 & 33 & 100 \\
\hline Resusitasi & 34.81 & 14 & 21 & 300 \\
\hline Tindakan & 21.5 & 180 & 95 & 300 \\
\hline Observasi & 65.55 & 41 & 40 & 200 \\
\hline Trauma Bedah & 30.68 & 38 & 35 & 300 \\
\hline
\end{tabular}

Dari Tabel I terlihat bahwa hasil pengukuran iluminasi tertinggi terdapat pada ruangan IRD Triage adalah sebesar $33 \%$, sedangkan hasil pengukuran yang terendah terdapat pada ruangan resusitasi yaitu $7 \%$. Keseluruhan dari hasil pengukuran disetiap ruangan IGD dapat dianalisa bahwa $80 \%$ tingkat pencahaayaan atau lux rata-rata untuk semua ruangan masih dibawah standar PERMENKES RI No.24 Tahun 2016

\section{B. Pengukuran Iluminasi Ruangan IBS}

Instalasi Bedah Sentral (IBS) merupakan salah satu bagian dari sistem pelayanan di rumah sakit yang penting dalam hal memberikan pelayanan kepada pasien yang memerlukan tindakan pembedahan baik untuk kasus kasus bedah terencana (efektif) maupun untuk kasus kasus bedah darurat (emergency). Ruangan yang berada di IBS memerlukan penerangan yang memadai selain dari lampu penerangan untuk operasi sebagaimana terlihat dari hasil pengukuran lampu yang terpasang pada Tabel II.

TABel II. Hasil PengukURAN ILUMinasi RuANGAN IBS

\begin{tabular}{|l|c|c|c|c|}
\hline \multirow{2}{*}{$\begin{array}{c}\text { Nama } \\
\text { ruang/sub } \\
\text { ruangan }\end{array}$} & \multirow{2}{*}{$\begin{array}{c}\text { Luas } \\
\text { Ruangan } \\
(\mathrm{m} 2) \mathrm{A}\end{array}$} & $\begin{array}{c}\text { Hasil Pengukuran } \\
\text { Siang } \\
\end{array}$ & $\begin{array}{c}\text { Malam } \\
(\text { Lux })\end{array}$ & $\begin{array}{c}\text { Standar Iluminasi } \\
\text { PERMENKES RI } \\
(\text { Lux })\end{array}$ \\
\hline OK 1 & 44.46 & 22 & 37 & 200 \\
\hline OK 2 & 33.64 & 23 & 43 & 200 \\
\hline OK 3 & 41.18 & 21 & 48 & 200 \\
\hline OK 4 & 33.64 & 21 & 50 & 200 \\
\hline OK 5 & 37.2 & 23 & 37 & 200 \\
\hline OK Mata & 34.22 & 31 & 33 & 200 \\
\hline OK CITO 1 & 26.55 & 60 & 63 & 200 \\
\hline OK CITO 2 & 35.4 & 59 & 64 & 200 \\
\hline
\end{tabular}

Dari Tabel II terlihat bahwa hasil pengukuran tingkat pencahayaan tertinggi terdapat pada ruangan OK Cito 1 dan 2 adalah sebesar $32 \%$ dari standar intensitas cahaya PERMENKESRI sebesar 200 lux. Sedangkan hasil pengukuran yang terendah terdapat pada ruangan OK Mata yaitu $17 \%$ dari standar tingkat pencahayaan PERMENKESRI sebesar 200 lux. Keseluruhan dari hasil pengukuran disetiap ruangan IBS dapat dianalisa bahwa tingkat pencahaayaan atau lux rata-rata untuk semua ruangan masih dibawah standar yaitu $80 \%$ dari standar yang telah ditentukan. Sehingga dapat dikategorikan dibawah standar berdasarkan PUIL 2011. 


\section{Pengukuran Iluminasi Ruangan IRDA}

Pelayanan di ruang gawat darurat anak (IRDA) termasuk daerah pelayanan kritis dan memerlukan pencahayaan ruangan yang baik. Hasil pengukuran untuk ruangan IRDA terlihat pada Tabel III.

TABEL III. HASIL PENGUKURAN ILUMINASI RUANGAN IRDA

\begin{tabular}{|c|c|c|c|c|}
\hline \multirow{2}{*}{$\begin{array}{l}\text { Nama } \\
\text { ruang/sub } \\
\text { ruangan }\end{array}$} & \multirow{2}{*}{$\begin{array}{l}\text { Luas } \\
\text { Ruangan } \\
(\mathrm{m} 2) \mathrm{A}\end{array}$} & \multicolumn{2}{|c|}{ Hasil Pengukuran } & \multirow{2}{*}{$\begin{array}{l}\text { Standar Iluminasi } \\
\text { PERMENKES RI } \\
\text { (Lux) }\end{array}$} \\
\hline & & $\begin{array}{l}\text { Siang } \\
(\text { Lux })\end{array}$ & $\begin{array}{c}\text { Malam } \\
(\text { Lux })\end{array}$ & \\
\hline Pasien & 33.64 & 50 & 29 & 300 \\
\hline
\end{tabular}

Dari Tabel III terlihat bahwa hasil pengukuran tingkat pencahayaan pada ruangan IRDA adalah sebesar $10 \%$ dari standar tingkat pencahayaan PERMENKES RI tahun 2016 sebesar 300 lux. Hasil pengukuran pada ruangan IRDA dapat dianalisa bahwa tingkat pencahaayaan ruangan masih dibawah standar.

\section{Pengukuran Iluminasi Ruangan PICU}

Paediatric Intensive Care Unit (PICU) merupakan suatu unit perawatan pasien anak dengan keadaan gawat atau berat yang sewaktu-waktu dapat meninggal, ruangan ini untuk pasien yang berumur di atas 29 hari sampai 14 tahun. Hasil pengukuran dapat dilihat pada Tabel IV.

TABEL IV. HASIL PENGUKURAN ILUMINASI RUANGAN PICU

\begin{tabular}{|c|c|c|c|c|}
\hline \multirow{2}{*}{$\begin{array}{c}\text { Nama } \\
\text { ruang/sub } \\
\text { ruangan }\end{array}$} & $\begin{array}{c}\text { Luas } \\
\text { Ruangan } \\
(\mathrm{m} 2) \mathrm{A}\end{array}$ & $\begin{array}{c}\text { Hasil Pengukuran } \\
(\text { Lux })\end{array}$ & $\begin{array}{c}\text { Malam } \\
(\text { Lux })\end{array}$ & $\begin{array}{c}\text { Standar Iluminasi } \\
\text { PERMENKES RI } \\
(\text { Lux })\end{array}$ \\
\hline Pasien & 106,92 & 58 & 42 & 250 \\
\hline
\end{tabular}

Terlihat pada Tabel IV bahwa hasil pengukuran tingkat pencahayaan pada ruangan PICU adalah sebesar 17\% dari standar tingkat pencahayaan PERMENKESRI sebesar 250 lux. Hasil pengukuran pada ruangan PICU dapat dianalisa bahwa tingkat pencahaayaan ruangan masih dibawah standar yaitu $80 \%$ dari standar yang telah ditentukan. Sehingga dapat dikategorikan dibawah standar berdasarkan PUIL 2011.

\section{E. Pengukuran Iluminasi Ruangan ICU}

Intensive Care Unit (ICU) merupakan ruangan khusus yang disediakan rumah sakit untuk merawat pasien dengan penyakit atau cedera serius.

Dari Tabel V terlihat bahwa hasil pengukuran tingkat pencahayaan tertinggi terdapat pada ruang 1 dan 2 adalah sebesar $16 \%$ dari standar tingkat pencahayaan PERMENKES RI tahun 2016 sebesar 250 lux. Hasil pengukuran disetiap ruangan ICU dapat dianalisa bahwa tingkat pencahaayaan ruangan masih dibawah standar.

TABEL V. HASIL PENGUKURAN ILUMINASI RUANGAN ICU

\begin{tabular}{|c|c|c|c|c|}
\hline \multirow{2}{*}{$\begin{array}{l}\text { Nama } \\
\text { ruang/sub } \\
\text { ruangan }\end{array}$} & \multirow{2}{*}{$\begin{array}{l}\text { Luas } \\
\text { Ruangan } \\
(\mathrm{m} 2) \mathrm{A}\end{array}$} & \multicolumn{2}{|c|}{ Hasil Pengukuran } & \multirow{2}{*}{$\begin{array}{c}\text { Standar Iluminasi } \\
\text { PERMENKES RI } \\
\text { (Lux) }\end{array}$} \\
\hline & & $\begin{array}{l}\text { Siang } \\
(\text { Lux })\end{array}$ & $\begin{array}{c}\text { Malam } \\
(\operatorname{Lux})\end{array}$ & \\
\hline Ruang 1 & 144.32 & 50 & 40 & 250 \\
\hline Ruang 2 & 103.84 & 44 & 40 & 250 \\
\hline
\end{tabular}

\section{F. Pengukuran Iluminasi Ruangan NICU}

Neonatel Intensive Care Unit (NICU) adalah ruang perawatan intensif untuk bayi (sampai umur 28 hari) dan anak -anak yang memerlukan pengobatan dan perawatan khusus guna mencegah dan mengobati terjadinya kegagalan organ-organ vital. Pengukuran intensitas cahaya pada Ruang NICU dilakukan dalam dua waktu yaitu siang dan malam hari.

TABEL VI. HASIL PENGUKURAN ILUMINASI RUANGAN NICU

\begin{tabular}{|l|c|c|c|c|}
\hline \multirow{2}{*}{$\begin{array}{c}\text { Nama } \\
\text { ruang/sub } \\
\text { ruangan }\end{array}$} & \multirow{2}{*}{$\begin{array}{c}\text { Luas } \\
\text { Ruangan } \\
(\mathrm{m} 2) \mathrm{A}\end{array}$} & $\begin{array}{c}\text { Hasil Pengukuran } \\
(\text { Lux })\end{array}$ & $\begin{array}{c}\text { Malam } \\
(\text { Lux })\end{array}$ & $\begin{array}{c}\text { Standar Iluminasi } \\
\text { PERMENKES RI } \\
(\text { Lux })\end{array}$ \\
\hline Ruang 1 & 44.08 & 53 & 64 & 250 \\
\hline Ruang 2 & 63.8 & 48 & 46 & 250 \\
\hline
\end{tabular}

Dari Tabel VI terlihat bahwa hasil pengukuran tingkat pencahayaan tertinggi terdapat pada ruang 1 adalah sebesar $26 \%$ dari standar tingkat pencahayaan PERMENKES RI tahun 2016 sebesar 250 lux. Sedangkan hasil pengukuran yang terendah terdapat pada ruang 2 yaitu $18 \%$ dari standar tingkat pencahayaan PERMENKES RI sebesar 250 lux. Keseluruhan dari hasil pengukuran disetiap ruangan NICU dapat dianalisa bahwa tingkat pencahaayaan atau lux ratarata untuk semua ruangan masih dibawah standar yaitu $80 \%$ dari standar yang telah ditentukan. Sehingga dapat dikategorikan dibawah standar berdasarkan PUIL 2011.

\section{G. Pengukuran Iluminasi Ruangan VK}

Verlos Kamer (VK) atau ruang bersalin adalah sebuah unit layanan pada rumah sakit yang berfungsi sebagai ruang persalinan selama 24 jam.

Dari Tabel VII terlihat bahwa hasil pengukuran tingkat pencahayaan tertinggi terdapat pada ruang ginecologi adalah sebesar 24\% dari standar tingkat pencahayaan PERMENKESRI sebesar 200 lux. Sedangkan hasil pengukuran yang terendah terdapat pada ruang observasi yaitu $21 \%$ dari standar tingkat pencahayaan PERMENKESRI sebesar 200 lux. Keseluruhan dari hasil pengukuran disetiap ruangan VK dapat dianalisa bahwa tingkat pencahaayaan atau lux rata-rata untuk semua ruangan masih dibawah standar $80 \%$.

TABEL VII. HASIL PENGUKURAN ILUMINASI RUANGAN VK

\begin{tabular}{|l|c|c|c|c|}
\hline \multirow{2}{*}{$\begin{array}{c}\text { Nama } \\
\text { ruang/sub } \\
\text { ruangan }\end{array}$} & \multirow{2}{*}{$\begin{array}{c}\text { Ruangan } \\
(\mathrm{m} 2) \mathrm{A}\end{array}$} & $\begin{array}{c}\text { Haiang } \\
(\text { Lux })\end{array}$ & $\begin{array}{c}\text { Malam } \\
(\text { Lux })\end{array}$ & $\begin{array}{c}\text { Hasil Pengukuran } \\
\text { PERMENKES RI } \\
\text { (Lux) }\end{array}$ \\
\hline Obstetri & 24.36 & 120 & 46 & 200 \\
\hline Ginecology & 24.36 & 110 & 47 & 200 \\
\hline Observasi & 64.96 & 58 & 41 & 200 \\
\hline Isolasi & 24.38 & 69 & 43 & 200 \\
\hline
\end{tabular}

\section{H. Pengukuran Iluminasi Ruangan CSSD}

Central Sterile Supply Department (CSSD) adalah instalasi yang melayani pelayanan sterilisasi dengan fasilitas untuk menerima, mendesinfeksi, memberikan, mengemas, mensteril, menyimpan dan mendistribusikan alal-alat (baik 
yang dapat dipakai berulang-ulang kali dan alat sekali pakai).

TABEL VIII. HASIL PENGUKURAN ILUMINASI RUANGAN CSSD

\begin{tabular}{|l|c|c|c|c|}
\hline \multirow{2}{*}{$\begin{array}{c}\text { Nama } \\
\text { ruang/sub } \\
\text { ruangan }\end{array}$} & $\begin{array}{c}\text { Luas } \\
\text { Ruangan } \\
(\mathrm{m} 2) \mathrm{A}\end{array}$ & \begin{tabular}{c}
$|c|$ \\
Hiang \\
\cline { 3 - 4 }
\end{tabular} & $\begin{array}{c}\text { Malam } \\
(\text { Lux })\end{array}$ & $\begin{array}{c}\text { Standar Iluminasi } \\
\text { PERMENKES RI } \\
\text { (Lux })\end{array}$ \\
\hline Precleaning & 16.82 & 37 & 40 & 200 \\
\hline Produksi Kasa & 16.82 & 133 & 36 & 200 \\
\hline Ruang Steril & 13.34 & 20 & 20 & 200 \\
\hline
\end{tabular}

Dari Tabel VIII terlihat bahwa hasil pengukuran tingkat pencahayaan tertinggi terdapat pada ruang precleaning adalah sebesar $20 \%$ dari standar tingkat pencahayaan PERMENKESRI sebesar 200 lux. Sedangkan hasil pengukuran yang terendah terdapat pada ruang sterill yaitu $10 \%$ dari standar tingkat pencahayaan PERMENKES RI tahun 2016 sebesar 200 lux. Keseluruhan dari hasil pengukuran disetiap ruangan CSSD dapat dianalisa bahwa tingkat pencahaayaan atau lux rata-rata untuk semua ruangan masih dibawah standar yaitu $80 \%$ dari standar yang telah ditentukan. Sehingga dapat dikategorikan dibawah standar berdasarkan PUIL 2011.

\section{Pembahasan}

Dari hasil pengukuran dan pengukuran keseluruhan disetiap ruangan pada gedung CMU dapat dianalisa bahwa tingkat pencahaayaan atau lux rata-rata untuk semua ruangan masih dibawah standar yaitu $80 \%$ dari standar yang telah ditentukan oleh PERMENKESRI No 24 Tahun 2016. Sehingga dapat dikategorikan dibawah standar berdasarkan PUIL 2011. Hal ini dikarenakan pengaruh luas ruangan yang tidak sesuai dengan jumlah lampu yang terpasang, kondisi lampu yang sudah kusam/kotor sehingga cahaya yang keluar dari lampu tidak dapat keluar secara maksimal, armatur pada titik lampu kurang bersih sehingga cahaya yang keluar terhalang oleh debu, dan warna dinding sudah mulai pudar sehingga visualisasi cahaya tidak keluar secara maksimal.

Penggunaan lampu yang kurang terang akan berdampak pada penglihatan para perawat dan dokter dalam menangani pasien dan juga penggunaan lampu yang begitu terang akan berdampak pada penglihatan beberapa pasien yang tidak begitu suka pada waktu istirahat tidur.

\section{KESIMPULAN}

Berdasarkan hasil pengamatan dan pengukuran intensitas cahaya yang telah dilakukan dapat diambil kesimpulan bahwa hasil observasi lapangan dengan menggunakan bantuan alat ukur berupa lux meter, besar intensitas cahaya pada masing-masing ruangan yang berada di gedung Central Medical Unit (CMU) pada Rumah Sakit Umum Daerah (RSUD) Prof. Dr. H. Aloei Saboe Kota Gorontalo, mengacu pada Standar Peraturan Menteri Kesehatan Republik Indonesia (PERMENKES RI) No. 24 Tahun 2016 Tentang Persyaratan Teknis Bangunan dan Prasarana Rumah Sakit. Tingkat pencahaayaan atau lux ratarata untuk semua ruangan masih dibawah standardisasi yaitu $80 \%$ dari standar yang telah ditentukan. Sehingga dapat dikategorikan dibawah standar berdasarkan PUIL 2011.

Untuk menghasilkan tingkat pencahayaan yang sesuai standar, masing-masing ruangan membutuhkan penambahan jumlah titik lampu. Hal ini dikarenakan pengaruh luas ruangan yang tidak sesuai dengan jumlah titik lampu yang terpasang, kondisi lampu yang sudah kusam/kotor sehingga cahaya yang keluar dari lampu tidak dapat keluar secara maksimal, armatur pada titik lampu kurang bersih sehingga cahaya yang keluar terhalang oleh debu, dan warna dinding sudah mulai pudar sehingga visualisasi cahaya tidak keluar secara maksimal

\section{REFFERENSI}

[1] RSAS, "Gambaran Umum RSUD Prof. Dr. H. Aloei Saboe, 2017.

[2] DIKES, "Profil Kesehatan", Dinas Kesehatan Provinsi Gorontalo, Vol. 3, 2013.

[3] R. P. B. Astuti, "Instruksi Presiden Republik Indonesia No 13 Tahun 2011 Tentang Penghematan Energi dan Air," Vol. 34, 2011.

[4] Guntur. B, Putra A. \& Madyono. G, "Analisis Intensitas Cahaya Pada Area Produksi Sesuai Dengan Standar Pencahayaan (Studi Kasus D PT . Lendis Cipta Media Jaya)," Vol. 10, No. 2, pp 115-124, 2017.

[5] Permenkes, 2016. Nomor 24 Tahun 2016 Tentang Persyaratan Teknis Bangunan Dan Prasarana Rumah Sakit, Indonesia.

[6] Suhendar, E. Efendi, Herudin, "Audit Sistem Pencahayaan dan Sistem Pendingin Ruangan di Gedung Rumah Sakit Umum Daerah (RSUD) Cilegon," Setrum, Vol. 2, No. 2, pp 21-27, 2013.

[7] Latifah, "Optimalisasi Pemakaian Daya Tersambung (KVA) Pada RSUD Dr . Abdul Aziz Singkawang," Jurnal ELKHA, Vol. 7, No. 2, pp 7-12, Oktober 2015.

[8] BSN. Persyaratan Umum Instalasi Listrik 2011 (PUIL 2011), Standar Nasional Indonesia, SNI 0225:2011.

[9] Tukiman, E. Karyanta, B. Santoso, "Perancangan Sistem Penerangan Bangunan Iradiator Gamma Kapasitas 200 kCi," Prima, Vol. 12, No. 1 , pp 38-44, Juni 2015. 